\title{
Formulation of a new phenytoin-containing mucoadhesive and evaluation of its healing effects on oral biopsy ulcers
}

\author{
Maryam Baharvand ${ }^{1}$, Ardeshir Lafzi ${ }^{2}$, Ahmad R-Mafi ${ }^{3}$, Jamileh-Bigom Taheri ${ }^{1}$, Hamed Mortazavi ${ }^{1}$, \\ Somayeh Alirezaei ${ }^{4^{*}}$ \\ ${ }^{1}$ Department of Oral Medicine, Dental School, Shahid Beheshti University of Medical Sciences, Tehran, Iran \\ ${ }^{2}$ Department of Periodontics, Dental School, Shahid Beheshti University of Medical Sciences, Tehran, Iran \\ ${ }^{3}$ Radiation Oncologist, Imam Hossein Hospital, Shahid Beheshti University of Medical Sciences, Tehran, Iran \\ ${ }^{4}$ Department of Oral Medicine, Islamic Azad University Dental Branch, Tehran, Iran \\ Email: ㄹ.s.somayehalirezaei@gmail.com
}

Received 11 November 2013; revised 14 December 2013; accepted 25 December 2013

Copyright (C 2014 Maryam Baharvand et al. This is an open access article distributed under the Creative Commons Attribution License, which permits unrestricted use, distribution, and reproduction in any medium, provided the original work is properly cited. In accordance of the Creative Commons Attribution License all Copyrights ( 2014 are reserved for SCIRP and the owner of the intellectual property Maryam Baharvand et al. All Copyright (C) 2014 are guarded by law and by SCIRP as a guardian.

\section{ABSTRACT}

Background and Objective: Several studies have shown the wound healing effect of topical phenytoin, which is applied by its effect on connective tissue intracellular matrix. However, there are still some controversies about its effect on various kinds of wounds, especially in the experimental models. This study is aimed at evaluating the effect of mucoadhesive paste compared to phenytoin mucoadhesive paste on wound healing after oral biopsy. Material and Methods: In this double blind randomized clinical trial, 20 patients who were eligible for oral biopsy were allocated into the case and control groups. After the biopsy, patients having ulcers ranging between one and two centimeters were treated by simple or $1 \%$ phenytoin mucoadhesive paste. All patients were instructed to apply their paste at least three times a day for five days after the biopsy. Patients in both groups were evaluated every other day for size of the ulcer, degree of pain and diameter of the inflammatory halo. Statistical analysis was done using SPSS software and MannWhitney test. Results: After the second and third appointments, it was observed that the rate of wound healing and decrease in the size of the ulcers were significantly quicker in the treatment group $(p=$ 0.001 and $p=0.003$ respectively) and the patients in the phenytoin group reported less pain. Diameter of the inflammatory halo was not significantly different between two groups. Conclusion: Applying 1\% phenytoin mucoadhesive paste on biopsy ulcers resulted in accelerated wound healing and decrease in pain, but had no effect on the diameter of the inflammatory

\footnotetext{
"Corresponding author.
}

halo.

\section{KEYWORDS}

Mucoadhesive Paste; Phenytoin; Oral Ulcer

\section{INTRODUCTION}

Refractory wounds (those that fail to respond to established medical and surgical treatment) are a common problem for many patients and represent a significant and growing challenge to the healthcare system. Clinical conditions or underlying diseases such as diabetes, sepsis, battle wounds, venous stasis, post-operation, and even post-biopsy wounds can cause significant morbidity or mortality due to delayed healing or wound dehiscence [1].

Infection due to new strains of drug resistant bacteria is the major impediment topical factor in the healing process, which prolongs treatment period [2].

The management of chronic wounds places an enormous drain on healthcare resources. For example, it has been estimated that chronic wound care costs about 10 billion dollars annually in North America. For each patient with a non-healing wound, on average, 12 dollars a day is spent with a mean treatment time of 192 days [2].

The emergence of new treatment methods and medications has provided a novel opportunity to improve the health and quality of life of patients with chronic, nonhealing wounds $[2,3]$.

Several studies have shown the healing effects of phenytoin on various kinds of chronic wounds such as pressure sores, diabetic ulcers, traumatic wounds, burns, and leprosy trophic ulcers [4-8]. 
The advantage of topical phenytoin over oral phenytoin is that the systemic side effects of the drug such as allergic reactions or gingival hyperplasia can be avoided.

The exact mechanism by which local use of phenytoin reduces the pain and discomfort is not known, however, blocking the sodium channels has been said to contribute to its analgesic effects. Besides, several studies suggest that phenytoin may be involved in the healing process at several levels including stimulating fibroblast proliferation, enhancing the formation of granulation tissue, decreasing collagenase activity, promoting deposition of collagen and other connective tissue components, decreasing bacterial contamination, and decreasing wound exudates $[3,9,10]$.

To our best knowledge, phenytoin as a mucoadhesive paste has not yet been evaluated in humans. The majority of previous researches were animal studies, and all of them have assessed the effects of either phenytoin powder or cream [11,12].

This study is aimed at evaluating the effect of mucoadhesive paste compared with phenytoin-containing mucoadhesive paste on wound healing after oral biopsy.

\section{MATERIALS AND METHODS}

\subsection{Type and Site of Study}

This double blind, randomized, placebo controlled clinical trial has been done on patients attending the oral medicine department of Shahid Beheshti University of Medical Sciences Dental School, who were candidate for an oral biopsy. Considering $\alpha=0.05$ and $\beta=0.2$ (power of study to be $80 \%$ ) the sample size estimated as 11 in each group. Patients who met the inclusion criteria were randomly classified into two groups of treatment and placebo.

\subsection{Subject Inclusion Criteria}

The inclusion criteria were as follows: 1) good general health; 2) not using any topical or systemic medication; 3) normal oral mucosa (except for the biopsied site); 4) non-smoker; 5) willing to participate in the trial.

\subsection{Subject Exclusion Criteria}

1) malignant-looking oral lesions; 2) necrotic lesions; 3) pemphigus-like lesions; 4) pregnancy.

Demographic data were collected by a data form.

The study protocol and informed consent process were approved by the ethical committee of Shahid Beheshti Dental School. Prior to commencing the study informed consent was obtained and documented for all subjects.

\subsection{Clinical Evaluations}

Oral biopsies were taken from the patients using biopsy punch number 8 (made by KiaMedical Company, Japan). We measured size of the ulcer, degree of wound closure, and the inflammatory halo at the day of biopsy, and every other day afterwards (totally three recall visits) by means of Williams probe (made by Williams Company, USA). The degree of pain was evaluated by patients' self-report using a 10 -cm visual analogue scale (VAS) on the day of biopsy, and then every other day till day 5 post-biopsy.

\subsection{Data Analysis}

Statistical analysis was done using Mann-Whitney test and $p<0.05$ was considered significant.

\section{RESULTS}

In both groups (treatment and placebo) there were 5 male and 5 female patients. Mean age of the patients was 45.2 \pm 11.3 and $47.1 \pm 15.5$ years in treatment and placebo groups respectively (Table 1 ), and their difference was not statistically significant ( $p=0.75)$.

On the first visit, all patients in both groups had a similar ulcer size $(10 \mathrm{~mm})$. On the second visit, the mean size of biopsy ulcers was $6.20 \pm 1.99$ and $8.5 \pm 1.78 \mathrm{~mm}$ in treatment and placebo groups respectively. This size reduced to $1.7 \pm 1.64$ and $5.1 \pm 2.64 \mathrm{~mm}$ in treatment and placebo groups respectively on the third visit.

As it is shown in Table 2, mean size of the ulcer on the second and third visit was significantly smaller in the treatment group ( $p=0.001$ and $p=0.003)$.

Size of the inflammatory halo was not significantly different between the two groups in different visits (Table 3$)$.

On the first visit, there was no difference between the VAS of the two groups ( $3 \pm 1.41$ and $3.5 \pm 2.32$ ); however, patients in the treatment group had a statistically significant lower VAS on the following visits.

On the second visit, VAS in the treatment and placebo groups was $0.82 \pm 0.7$ and $3.03 \pm 2.9$ respectively ( $p=$ $0.035)$. On the third visit, patients in the treatment group had no pain (VAS $=0$ ), while patients in the placebo group had VAS $=2.45 \pm 1.4(p=0.043)$ (Table 4$)$.

\section{DISCUSSION}

Non-healing and chronic wounds are significant healthcare problems in today's medical practice. Various methods and medications have been used so far to alleviate the symptoms and improve the healing process in chronic, non-healing ulcers; however, the outcomes of existing methods are still far from optimal [1,2].

Several studies have shown the benefits of applying topical phenytoin on accelerating the healing process and Several studies have shown the benefits of applying topical phenytoin on accelerating the healing process and 
Tab le 1. Frequency of patients based on gender and age.

\begin{tabular}{cccc}
\hline \multirow{2}{*}{ Group } & \multicolumn{2}{c}{ Gender } & \multirow{2}{*}{ Age (mean \pm SD) } \\
\cline { 2 - 3 } & Male & Female & \\
\hline Treatment & 5 & 5 & $45.2 \pm 11.3$ years \\
Placebo & 5 & 5 & $47.1 \pm 15.5$ years \\
\hline
\end{tabular}

Table 2. The mean of ulcer size on second and third visits.

\begin{tabular}{|c|c|c|c|}
\hline Group Size & $\begin{array}{l}\text { Mean size on } \\
\text { the 2nd visit }\end{array}$ & $\begin{array}{l}\text { Mean size on } \\
\text { the 3rd visit }\end{array}$ & $P$ value \\
\hline Treatment & $6.20 \pm 1.99 \mathrm{~mm}$ & $1.7 \pm 1.64 \mathrm{~mm}$ & 0.003 \\
\hline Placebo & $8.5 \pm 1.78 \mathrm{~mm}$ & $5.1 \pm 2.64 \mathrm{~mm}$ & 0.001 \\
\hline
\end{tabular}

Table 3. The mean of inflammatory halo size on different visits.

\begin{tabular}{cccc}
\hline Sroup & $\begin{array}{c}\text { Mean size on } \\
\text { the 1st visit }\end{array}$ & $\begin{array}{c}\text { Mean size on } \\
\text { the 2nd visit }\end{array}$ & $\begin{array}{c}\text { Mean size on } \\
\text { 3rd visit }\end{array}$ \\
\hline Treatment & $2.8 \pm 1.03 \mathrm{~mm}$ & $1.2 \pm 1.23 \mathrm{~mm}$ & $0.8 \pm 1.87 \mathrm{~mm}$ \\
Placebo & $2.8 \pm 0.63 \mathrm{~mm}$ & $2 \pm 1.05 \mathrm{~mm}$ & $0.8 \pm 0.79 \mathrm{~mm}$ \\
$P$ value & 0.739 & 0.190 & 0.315 \\
\hline
\end{tabular}

Table 4. The mean of VAS on different visits.

\begin{tabular}{cccc}
\hline Sroup & $\begin{array}{c}\text { Mean VAS on } \\
\text { the 1st visit }\end{array}$ & $\begin{array}{c}\text { Mean VAS on } \\
\text { the 2nd visit }\end{array}$ & $\begin{array}{c}\text { Mean VAS on } \\
\text { the 3rd visit }\end{array}$ \\
\hline Treatment & $3 \pm 1.41$ & $0.82 \pm 0.7$ & 0 \\
Placebo & $3.5 \pm 2.32$ & $3.03 \pm 2.9$ & $2.45 \pm 1.4$ \\
P value & 0.739 (NS) & $0.035(\mathrm{~S})$ & $0.006(\mathrm{~S})$ \\
\hline
\end{tabular}

NS: Non Significant; S: Significant.

alleviating the symptom in different types of ulcers, including decubitus ulcers, venous stasis ulcers, diabetic ulcers, traumatic wounds, burns, and leprosy trophic ulcers.

In the study on 47 patients with decubitus ulcers, Rhodes et al. found that topical phenytoin therapy resulted in a shorter time to complete healing and formation of granulation tissue when compared with DuoDerm dressings or triple antibiotic ointment applications [4].

Fonska et al. reported that phenytoin sodium 2\% solution was beneficial for pyoderma gangrenosum with various etiologies, and it enhanced the healing of the ulcer especially when the patient had treatment resistant disease [8].

Hasamin et al. studied the wound healing effect of $1 \%$ Phenytoin cream in the wounds of rats. In their study, 20 male Wistar albino rats were subjected to excisional wounds measuring $500 \mathrm{~mm}^{2}$ on the back and then randomized to control and treatment groups. The control group received no drug treatment till the end of the study. $1 \%$ Phenytoin cream was applied to the wounds of rats in the group B and continued till the $16^{\text {th }}$ day of the study. They calculated the percentages of the healing wounds by Walker formula after measurement of the wound area. They found statistically significant reduction in average wound area in Group B on Days 4, 8, 12, and 16 of the experiment in comparison to Group A [12].

Kadkhodazadeh et al. study in 2012 showed that phenytoin suspension can effectively accelerate the process of healing at the donor site and reduce pain following periodontal surgeries. In their study, those patients who were treated phenytoin suspension showed significantly faster healing at days 14 and 28; and Pain Score was significantly lower in patients treated with phenytoin [11].

Baharvand et al. [13] used 0.5\% phenytoin mouthwash in patients under chemotherapy. In that study, administration was supervised by the department nurses four times a day and each time patients rinsed $10 \mathrm{ml}$ of the solution in their mouths for 1 minute, and then expectorated. Their study failed to show any advantage of using $0.5 \%$ phenytoin mouthwash to reduce pain and discomfort.

Hamian et al. compared the effects of $1 \%$ phenytoin mouthwash with normal saline $0.9 \%$ in patients under head and neck radiotherapy. In that double blind study, patients were advised to rinse their mouth three times a day with $10 \mathrm{ml}$ of their mouthwash, and not to eat or drink for half an hour after using the mouthwash. Patients in the treatment group (phenytoin mouthwash) had a better quality of life and less pain in all subsequent visits [14].

Based on these findings, we decided to use $1 \%$ phenytoin in our study, and furthermore, to use "paste" as the drug vehicle in order to increase the treatment efficacy. Applying the drug in the form of paste, as compared to cream or elixir, can avoid loss of drug due to wash out with saliva and prolongs contact of the formulation with the oral mucosa allowing a longer duration for absorption [15-17]. Besides, this formulation can act as a wound-dressing, which can further alleviate patients' pain and discomfort [4].

Results of our study showed that applying phenytoin mucoadhesive paste on oral ulcers, compared to ordinary paste, can significantly reduce the pain, and improve the process of wound healing. This is in accord with the results of many previous studies.

The mean diameter of the inflammatory halo did not reach the statistical significance between the two groups. In our opinion, this is not an important issue, as it has nothing to do with the patients' symptoms and quality of life. Meanwhile, phenytoin paste might have applied its microscopic anti inflammatory effect on wound sites which was not evident clinically as shown by Modag- 
hegh, El Zayat, and Moy $[10,18,19]$.

Several studies have shown that Visual Analog Scale (VAS) is a valuable method of pain measurement [20]. Reported VAS in the treatment group was significantly lower than that of the placebo group, which means the treatment group had less pain and discomfort on the second and third visits. More importantly, patients of the treatment group had VAS $=0$ in the third visit, which means having no pain, while other patients still were suffering from pain at that time.

The importance of this study was that no systemic treatment was used; therefore, side effects of such a treatment including gingival hyperplasia and somnolence were avoided. Furthermore, unlike phenytoin creams, using phenytoin paste in this study resulted in less drug washout and hence, better healing effect on ulcers.

\section{CONCLUSION}

In conclusion, mucoadhesive phenytoin paste has shown promising results in reducing pain and discomfort in oral ulcers. Further studies in various types of oral ulcers can further clarify its role in the management of oral ulcers in the future.

\section{CONFLICTS OF INTERESTS}

None.

\section{ACKNOWLEDGEMENTS}

This article was based on a post-graduate dissertation number 707 accomplished by Dr Somayeh Alirezaei under the supervision of Dr Maryam Baharvand, Dr Ardeshir Lafzi at Oral \& Maxillofacial Department, Shahid Beheshti University of Medical Sciences Dental School in the academic year of 2012-2013. The study was supported financially by Deputy of Research of Shahid Beheshti Dental School.

\section{REFERENCES}

[1] Jarrahi, M. and Vafaei, A. (2004) Topical phenytoin cream on linear incisional wound healing in albino rats. DARU, 2, 223-227.

[2] Meena, K., Mohan, A.V., Sharath, B., Somayaji, S.N. and Bairy, K.L. (2011) Effect of topical phenytoin on burn wound healing in rats. Indian Journal of Experimental Biology, 49, 56-59.

[3] DaCosta, M.L., Regan, M.C., al Sader, M., Leader, M. and Bouchier-Hayes, D. (1998) Diphenylhydantoin sodium promotes early and marked angiogenesis and results in increased collagen deposition and tensile strength in healing wounds. Surgery, 123,287-293.

http://dx.doi.org/10.1016/S0039-6060(98)70181-3

[4] Rhodes, R.S., Heyneman, C.A., Culbertson, V.L., Wilson, S.E. and Phatak, H.M. (2001) Topical phenytoin treatment of stage II decubitus ulcers in the elderly. Annals of Pharmacotherapy, 35, 675-681.

\section{http://dx.doi.org/10.1345/aph.10267}

[5] Chan, F.C., Kennedy, C., Hanson, R.P., O’Sullivan, B., Kelly, J. and Bouchier-Hayes, D. (2007) Topical diphenylhydantoin sodium can improve healing in a diabetic incisional animal wound model. Journal of Wound Care, 16, 359-363.

[6] Malhotra, Y.K. and Amin, S.S. (1991) Role of topical phenytoin in trophic ulcers of leprosy in India. International Journal of Leprosy and Other Mycobacterial Diseases, 59, 337-338.

[7] Yadav, J.K., Singhvi, A.M., Kumar, N. and Garg, S. (1993) Topical phenytoin in the treatment of split-thickness skin autograft donor sites: a comparative study with polyurethane membrane drape and conventional dressing. Burns, 19, 306-310. http://dx.doi.org/10.1016/0305-4179(93)90118-R

[8] Fonseka, H.F., Ekanayake, S.M. and Dissanayake, M. (2010) Two percent topical phenytoin sodium solution in treating pyoderma gangrenosum: A cohort study. International Wound Journal, 7, 519-523. http://dx.doi.org/10.1111/j.1742-481X.2010.00725.x

[9] Ashima Bhatia, M.D. and Surya Prakash, D.V.D. (2009) Topical phenytoin for wound healing. Dermatology Online Journal, 10, 5.

[10] Modaghegh, S., Salehian, B., Tavassoli, M., Djamshidi, A. and Rezai, A.S. (1989) Use of phenytoin in healing of war and non-war wounds. A pilot study of 25 cases. International Journal of Dermatology, 28, 347-350. http://dx.doi.org/10.1111/j.1365-4362.1989.tb01363.x

[11] Kadkhodazadeh, M., Khodadoustan, A., Seif, N.S. and Amid, R. (2012) Short term effect of 1\% topical phenytoin suspension on the pain and wound dimensions of donor site after free gingival graft. Journal of Dental School, 29, 366-371.

[12] Hasamnis, A., Mohanty, B. and Muralikrishna, P.S. (2010) Evaluation of wound healing effect of topical phenytoin on excisional wound in albino rats. Journal of Young Pharmacy, 2, 59-62. http://dx.doi.org/10.4103/0975-1483.62215

[13] Baharvand, M., Sarrafi, M., Alavi, K., Jalali, M.E. (2010) Efficacy of topical phenytoin on chemotherapy-induced oral mucositis; a pilot study. Daru, 18, 46-50.

[14] Hamian, M., Baharvand, M., Mousavizadeh, M., Mortazavi, A. and Ameri, A. (2011) Effect of topical phenytoin on chemo radiotherapy-induced mucositis. Tehran, Shahid Beheshti University of Medical Sciences, 37 p. Dissertation.

[15] Trevor, A.J., Katzung, B.G., Masters, S.B. and KnuideringHall, M. (2013) Antiseizure drugs. In: Trevor, A.J., Katzung, B.G., Masters, S.B. and Knuidering-Hall, M., Eds., Katsung \& Trevors' Pharmacology, 10th Edition, McGraw Hill, 217-225.

[16] Nash, A.S., Thompson, H. and Bogan, J.A. (1977) Phenytoin toxicity: A fetal case in a dog with hepatitis and joundice. Veterinary Record, 100, 280-281. http://dx.doi.org/10.1136/vr.100.14.280

[17] Papich, M.G. (2009) Anticonvulsant drugs. In: Riviere, J.E. and Papich, M.G., Eds., Veterinary pharmacology and 
therapeutics. 9th Edition, Wiley Blackwell, Iowa, 493509.

[18] El-Zayat, S.G. (1989) Preliminary experience with topical phenytoin in wound healing in war zone. Military Medicine, 28, 347-350.

[19] Moy, L.S., Tan, E.M.L., Holness, R. and Uitto, J. (1985) Phenytoin modulates connective tissue metabolism and cell proliferation in human skin fibroblast cultures. Arc- hives of Dermatology, 121, 79-83.

http://dx.doi.org/10.1001/archderm.1985.0166001008302 $\underline{4}$

[20] Williams, V.S.L., Morlock, R.J. and Feltner, D. (2010) Psychometric evaluation of a visual analog scale for the assessment of anxiety. Health Quality of Life Outcomes, 8, 57. http://dx.doi.org/10.1186/1477-7525-8-57 